\title{
Iluminação natural: indicações de profundidade-limite de ambientes para iluminação natural no Regulamento Técnico da Qualidade do Nível de Eficiência Energética de Edifícios Residenciais - RTQ-R
}

Daylighting: guidelines for room depth limits in the Technical Regulation for Energy Efficiency Labelling of Residential Buildings

\section{Milena Sampaio Cintra de Albuquerque Cláudia Naves David Amorim}

Resumo no Brasil em agosto de 2010, dando sequência ao Programa Brasileiro de Etiquetagem do Inmetro voltado para edificações. Com relação a aspectos bioclimáticos da arquitetura dos edifícios, tais como iluminação natural, buscou-se desenvolver alguns pré-requisitos e bonificações para os ambientes, de forma que esses aspectos fossem considerados na avaliação de edificações residenciais. Neste artigo, apresentam-se o método e os resultados que geraram as indicações relativas à bonificação de iluminação natural presentes no Regulamento. O método utilizado incluiu 336 simulações computacionais dinâmicas com o software DaySim, com o objetivo de investigar a influência de variáveis arquitetônicas no desempenho da iluminação natural, mais especificamente a profundidade dos ambientes e as proteções solares. As simulações foram realizadas para 11 cidades brasileiras, abarcando 11 diferentes latitudes e 4 zonas bioclimáticas (ZB 1 , ZB 3, ZB 4 e ZB 4). Os resultados geraram indicações sobre a profundidade-limite de ambientes, que foram adotadas como parâmetros para concessão da bonificação de iluminação natural no RTQ-R.

Palavras-chave: Iluminação natural. Profundidade de ambientes. RTQ-R.

Bonificações. Albuquerque Laboratório de Controle Ambiental e Eficiência Energética, Faculdade de Arquitetura e Urbanismo Universidade de Brasília Campus Universitário Darcy Ribeiro

ICC Norte - Gleba A, Asa Norte Brasilia - DF - Brasi CEP 70910-900 Tel.: (61) 3107-7453

E-mail: msampaio@unb.br

Cláudia Naves David Amorim Laboratório de Controle Ambiental e Eficiência Energética, Faculdade de Arquitetura e Urbanismo Universidade de Brasília E-mail: clamorim@unb.br

Recebido em 10/10/11 Aceito em 23/04/12

\section{Abstract}

Daylighting is an important resource to promote well being and environmental quality, and has also a significant impact on energy use. The Technical Regulations for Energy Efficiency Labeling of Residential Buildings (RTQ-R) was published in Brazil in August 2010, as a part of INMETRO's Brazilian Labeling Program. Concerning aspects of bioclimatic architecture such as daylight, some prerequisites and bonus were developed to be considered in the evaluation of residential buildings. This article presents the method and the results that produced the indications related to the daylight bonus that are established in that Regulation. The method included 336 computer simulations using the software DaySim, in order to investigate the variables that influence daylight performance, specifically regarding room depth and solar protection. The simulations were performed for 11 Brazilian cities, covering 11 different geographical latitudes and four bioclimatic zones ( $Z B$ 1, ZB 3, ZB 4 and $Z B 11)$. The results generated guidelines on room depth limits, which were adopted as parameters for granting daylight bonus in the RTQ-R regulations.

Keywords: Daylighting. Room depth. RTQ-R. Bonus. 


\section{Introdução}

A luz natural em edificações tem papel importante para atender a uma série de requisitos funcionais, ambientais e econômicos. Portanto, incorporar a luz natural de forma coerente, otimizando seus benefícios e minimizando impactos negativos, torna-se crucial (AMORIM, 2007).

O uso adequado da iluminação natural no ambiente interno promove o conforto psicológico, tornando o ambiente agradável e produtivo, proporcionando melhores condições de saúde humana, pois exerce influência importante no ciclo biológico das pessoas (MARTAU, 2009; FIGUEIRÓ, 2010).

Por outro lado, o consumo de energia nas edificações vem crescendo, especialmente em edificações residenciais. O consumo de energia neste setor aumentou 6,5\% no biênio de 2008 e 2009, enquanto no setor industrial caiu 5,5\% no mesmo período (MINISTÉRIO..., 2009). O crescimento do consumo no setor residencial ocorreu principalmente devido às políticas de redução de impostos para alguns bens de consumo durante a crise econômica, além do aumento da renda per capita no país.
Apesar da importância da luz natural em edificações para o conforto do usuário e a necessidade de tornar as edificações mais eficientes, o Brasil ainda está em processo de desenvolvimento de estudos que indiquem efetivamente o que projetistas devem considerar para se beneficiar da luz natural. Há uma carência de conhecimento em relação às variáveis arquitetônicas que influenciam no desempenho da luz natural no espaço construído:

(a) qual a profundidade máxima do ambiente para que ele seja iluminado adequadamente com luz natural? e

(b) qual o impacto das proteções solares na profundidade alcançada pela luz natural?

No contexto internacional, algumas recomendações relacionam, por exemplo, a altura das aberturas e a profundidade-limite de ambientes internos para o aproveitamento da luz natural. O Quadro 1 resume algumas referências internacionais relativas ao limite da profundidade do ambiente em relação à altura da verga da janela para garantir iluminação natural.

\begin{tabular}{|l|l|}
\hline \multicolumn{1}{|c|}{\begin{tabular}{c}
\multicolumn{1}{|c|}{ Indicações gerais da literatura internacional } \\
sobre iluminação natural
\end{tabular}} & \multicolumn{1}{c|}{ Referência } \\
\hline $\begin{array}{l}\text { A luz natural em um edifício será significativa somente em cerca de } \\
2 \text { vezes o pé-direito de uma fachada envidraçada. }\end{array}$ & $\begin{array}{l}\text { A Green Vitruvius } \\
\text { (COFAIGH et al., 1999, p. 72) }\end{array}$ \\
\hline $\begin{array}{l}\text { A profundidade máxima da área com iluminação natural } \\
\text { corresponde a 2,5 vezes a diferença entre a verga da janela e a } \\
\text { altura do plano de trabalho. }\end{array}$ & $\begin{array}{l}\text { DIN V 18599: 4 } \\
\text { (DEUTSCHES..., 2005) }\end{array}$ \\
\hline $\begin{array}{l}\text { Manter a profundidade dos ambientes entre 1,5 e 2 vezes a altura da } \\
\text { verga da janela para níveis adequados de iluminação e boa } \\
\text { distribuição da luz. }\end{array}$ & $\begin{array}{l}\text { Tips for Daylighting } \\
\text { (O’CONNOR et al., 1997) }\end{array}$ \\
\hline $\begin{array}{l}\text { Ambientes com profundidade de 1,5 vez a altura da verga da janela } \\
\text { permitem que a luz do sol gere níveis adequados de iluminação e } \\
\text { boa distribuição da luz. }\end{array}$ & $\begin{array}{l}\text { Daylighting Guide for Canadian } \\
\text { Commercial Buildings } \\
\text { (ENERMODAL..., 2002, p. 23) }\end{array}$ \\
\hline $\begin{array}{l}\text { Há uma relação direta entre a altura da verga da janela e a } \\
\text { profundidade de penetração da luz natural. Uma iluminação } \\
\text { adequada normalmente penetra 1,5 vez a altura da verga da janela, } \\
\text { podendo penetrar em até } 2 \text { vezes considerando-se raios solares } \\
\text { diretos. }\end{array}$ & $\begin{array}{l}\text { Daylighting Guide for Buildings } \\
\text { (ROBERTSON, 2005, p. 4) }\end{array}$ \\
\hline $\begin{array}{l}\text { Para evitar grandes variações entre níveis de iluminância (maiores } \\
\text { que 25:1), a distância da parede da janela à parede interna deveria } \\
\text { ser limitada a 2 vezes a altura da verga da janela com vidros } \\
\text { incolores. }\end{array}$ & $\begin{array}{l}\text { IESNA Lighting Handbook } \\
\text { (IESNA, 2000, p. 8-24) }\end{array}$ \\
\hline
\end{tabular}

Quadro 1 - Resumo das indicações na literatura internacional sobre o limite da profundidade do ambiente em relação à altura da verga da janela

Fonte: adaptado de Reinhart (2005). 
Essas indicações são amplamente utilizadas por projetistas em geral, apesar de não informarem o que garantem em iluminação natural no ambiente e de não possuírem justificativas baseadas em pesquisas para os valores indicados (REINHART, 2005). A ampla utilização acontece devido à simplicidade delas (não exigem cálculos) e de sua relevância para o projeto (ligação direta entre as proporções do ambiente e o tamanho da área iluminada naturalmente) (REINHART, 2005). Diante disso, verifica-se a importância de estudos que forneçam indicações simples para iluminação natural em edifícios, embasadas em conceitos científicos, adequadas às diversas tipologias e adaptadas aos contextos climáticos. Dessa forma, o objetivo deste artigo é verificar a influência da profundidade do ambiente e das proteções solares no comportamento da luz natural em ambientes residenciais, considerando o contexto territorial brasileiro, de forma a contribuir para as boas práticas no uso da luz natural em arquitetura.

\section{Iluminação natural e arquitetura}

No contexto brasileiro, existe carência de conhecimento em relação às variáveis arquitetônicas que influenciam no desempenho da luz natural no espaço construído, como a área de abertura para a iluminação de ambientes sem que haja excesso de incidência de carga térmica, a profundidade máxima dos ambientes para que haja iluminação adequada com luz natural e a influência de proteções solares no alcance da luz natural nos ambientes. São inúmeras as lacunas que não são abordadas de maneira satisfatória em normas, manuais ou códigos de obras e edificações.

A Associação Brasileira de Normas Técnicas (ABNT) possui atualmente 14 normas que regulamentam a questão de iluminação de interiores. Entre elas, a NBR 15215-1, 2, 3 e 4 (ABNT, 2005a; 2005b; 2005c) aborda o uso da luz natural em edificações, incluindo os procedimentos de cálculo para a estimativa da disponibilidade de luz natural e o procedimento de cálculo para a determinação da iluminação natural em ambientes internos. Essa norma foi um grande passo para o uso da iluminação natural em edificações, no entanto não é de fácil utilização para a prática projetual e não relaciona diretamente as condições de iluminação natural com as variáveis arquitetônicas, embora a Parte 3, "Procedimento de cálculo para determinação da iluminação natural em ambientes internos”, apresente um método gráfico que permite a identificação de tais relações.
Na NBR 15575-1 (ABNT, 2008), Desempenho para Edifícios Habitacionais de até 5 Pavimentos, são abordadas diversas questões sobre 0 desempenho de edificações residenciais, com o foco “[...] nas exigências dos usuários para o edifício habitacional e seus sistemas, quanto ao seu comportamento em uso [...]" (ABNT, 2008, p. 3). No item Conforto Lumínico, essa norma define que durante o dia os ambientes de permanência prolongada, cozinhas, área de serviço e banheiros devem atender ao nível mínimo de iluminamento de 60 lux apenas com iluminação natural. Apesar de essa norma ainda não estar em vigor, é respaldada pela indicação da Norma alemã DIN 5034 (DEUTSCHES..., 1997), que recomenda que, para iluminação natural, sejam utilizados $60 \%$ do indicado pela norma de iluminação artificial (ALUCCI, 2007). A norma brasileira NBR 5413 (ABNT, 1992) indica como mínimo para ambientes residenciais 100 lux, portanto 60 lux seria o mínimo indicado para iluminação natural.

Fernandes (2009) realizou uma pesquisa acerca dos códigos de obras brasileiros e verificou que as exigências para iluminação natural estão relacionadas com as áreas de aberturas mínimas em função da área de piso de cada ambiente. No entanto, não há estudos mais aprofundados que justifiquem as áreas adotadas. A autora verificou, por exemplo, que o Código de Obras do Distrito Federal exige área de abertura de $1 / 8$ da área de piso para ambientes de permanência prolongada; já nos Modelos de Código de Obras elaborado pelo Ibam/Procel, nos Códigos de Obras das cidades de Salvador, Porto Alegre, Paracatu, Natal, Florianópolis e no Caderno de Encargos do Rio de Janeiro a proporção exigida é de 1/6.

\section{Simulações computacionais para análise da iluminaçao natural em edificações}

Devido à variabilidade da luz natural, torna-se muitas vezes difícil a análise de seu comportamento em ambientes internos. Reinhart, Mardaljevic e Rogers (2006) mencionam que muitas metodologias de avaliação da luz natural que consideram apenas o fator de luz do dia e vista para o exterior e que não têm o objetivo de necessariamente promover um bom projeto em integração com a iluminação natural, mas conduzem a uma melhor filosofia para projetar. Nessas metodologias, alguns parâmetros importantes são negligenciados, como a sazonalidade da luz natural. Assim, os autores apontam para uma abordagem considerando medidas dinâmicas para o desempenho da iluminação natural, que consideram a 
especificidade local, a interação dinâmica entre o edifício, seus ocupantes e as condições climáticas e do céu ao longo de um ano.

As medidas dinâmicas da iluminação natural baseiam-se em dados de radiação solar anual para um local específico, oriundos de um arquivo climático, e são geradas por meio de simulação computacional. Os resultados são apresentados em uma série de dados de iluminâncias e luminâncias dentro da edificação. A principal vantagem das medidas de desempenho dinâmico em comparação com as medidas estáticas é que as primeiras consideram a quantidade e a natureza das variações diárias e sazonais da iluminação natural para determinado edifício, em determinado sítio, juntamente com eventos meteorológicos irregulares.

Segundo Reinhart (2005), na última década, ferramentas de simulação de iluminação natural de medidas dinâmicas tornaram-se mais sofisticadas e mais fáceis de serem utilizadas. O software Daysim, desenvolvido no Conselho Nacional de Pesquisas do Canadá (NRCC) e no Fraunhofer Institute for Solar Energy Systems, utiliza o Radiance, cujo algoritmo é baseado no backward raytracer, e os modelos de céu de Perez. Estes permitem prever de maneira confiável a quantidade de luz natural em edifícios com geometria complexa (MARDALJEVIC, 2000; REINHART; WALKENHORST, 2001), calculando perfis de iluminância e luminância anual em forma de medidas dinâmicas do desempenho da luz natural.

Devido a todas essas características e ao fato de existirem trabalhos anteriores utilizando de maneira eficaz esse software (DIDONÉ, 2009), ele foi adotado para o presente estudo.

\section{Regulamento de eficiência energética brasileiro}

No Brasil, foi publicado em 2009 o Regulamento Técnico da Qualidade do Nível de Eficiência Energética de Edifícios Comerciais, de Serviços e Públicos (RTQ-C), e em setembro de 2010 foi publicado o Regulamento Técnico da Qualidade do Nível de Eficiência Energética de Edifícios Residenciais (RTQ-R).

O RTQ-R apresenta os critérios para classificação completa do nível de eficiência energética do edifício residencial através de classificações parciais da envoltória (que inclui a iluminação natural e a ventilação natural) e o sistema de aquecimento de água. A classificação é realizada na escala da unidade habitacional, da edificação unifamiliar, de edificações multifamiliares e das áreas comuns de edificações multifamiliares. Uma equação pondera esses sistemas através de pesos estabelecidos no regulamento e permite somar à pontuação final bonificações, que podem ser adquiridas mediante o uso da iluminação natural, da ventilação natural, do uso racional da água, do uso de equipamentos certificados pelo Programa Brasileiro de Etiquetagem, entre outros.

Neste artigo, apresentam-se o método e os resultados que geraram as indicações relativas à bonificação de iluminação natural presentes no RTQ-R. O método utilizado incluiu 336 simulações computacionais dinâmicas com o software DaySim, com o objetivo de investigar a influência de variáveis arquitetônicas no desempenho da iluminação natural, mais especificamente a profundidade dos ambientes e as proteções solares.

\section{Metodologia}

A seguir, descrevem-se as etapas da metodologia utilizada para o desenvolvimento do estudo.

\section{Desenvolvimento e características do modelo-base}

Para este estudo foi definido e construído um modelo-base de um ambiente residencial hipotético de $23 \mathrm{~m}^{2}$. O modelo tem a mesma área dos modelos utilizados para os testes de desempenho térmico e energético do RTQ-R, mas com profundidade aumentada, para permitir melhor análise da penetração da luz natural. O modelo tem uma abertura com área de $3,81 \mathrm{~m}^{2}$, equivalente a 1/6 da área do piso, acompanhando, assim, a indicação da maioria dos códigos de obras brasileiros (FERNANDES, 2009). A abertura tem dimensões de $3 \mathrm{~m} \times 1,27 \mathrm{~m}$ e peitoril de $1 \mathrm{~m}$ de altura, com vidro incolor. A Figura 1 e a Tabela 1 apresentam o modelo e as características de refletância das superfícies, conforme default do programa e coerentes com materiais de acabamento comumente encontrados (tetos pintados em cor branca; piso em cerâmica vermelha; paredes pintadas em cores médias; vidro incolor simples).

Para verificar a profundidade de penetração da luz natural no ambiente na altura do plano de trabalho, foi estabelecida uma malha de pontos de acordo com o indicado pela NBR 15215-4 (2005d), apesar de não se tratar de procedimento experimental. O ambiente interno foi, portanto, dividido em partes iguais, com espaçamento de $1 \mathrm{~m}$, totalizando 18 pontos de medição (Figura 2). A altura da malha é a altura do plano de trabalho $(0,75 \mathrm{~m})$. 


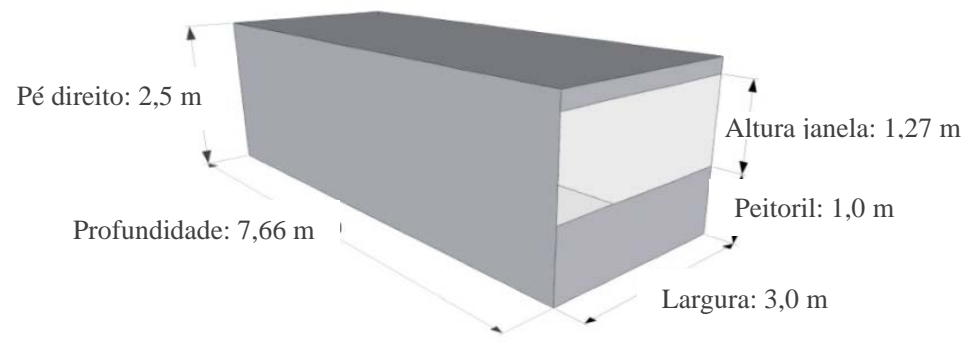

Figura 1 - 3D do modelo-base

Tabela 1 - Característica das superfícies

\begin{tabular}{l|l}
\hline Superfície & \multicolumn{1}{|c}{ Característica } \\
\hline Pisos & $30 \%$ de refletância \\
Tetos & 84\% de refletância \\
Paredes & $58 \%$ de refletância \\
Vidro & Transmissão luminosa de 89\% \\
\hline
\end{tabular}

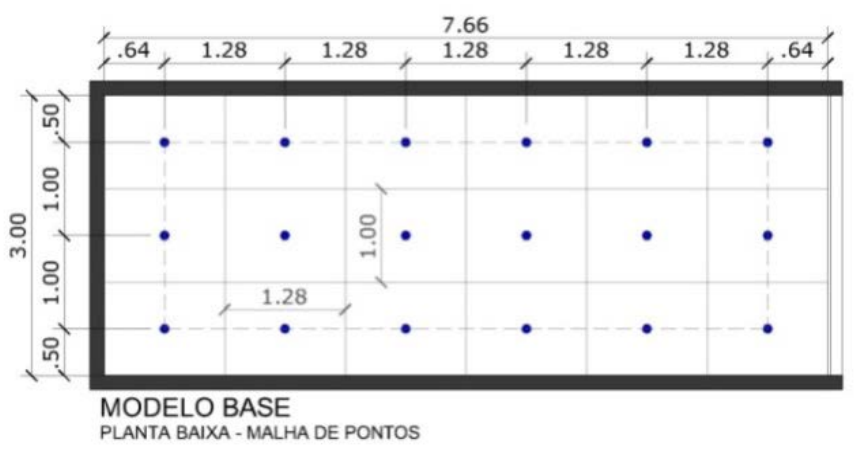

Figura 2 - Malha de pontos de medição dos modelos

\section{Variáveis da simulação}

Além das características físicas do modelo, para avaliação do comportamento da luz natural, foram definidas as seguintes variáveis de simulação:

(a) iluminância de projeto: exigência mínima de iluminância fornecida apenas com luz natural (REINHART; MARDALJEVIC; ROGERS, 2006). Para verificar a influência dessa variável foram analisados os resultados das simulações em duas condições distintas de iluminância de projeto. Inicialmente, foi determinada uma iluminância de projeto de 100 lux, que, segundo Reinhart (2005), é o valor mínimo de iluminância natural útil. Posteriormente foi utilizado o valor de 60 lux, nível mínimo de iluminância indicado pela NBR 15575-1 (2008) para ambientes de permanência prolongada, banheiros, cozinhas e área de serviço de edificações residenciais de até cinco pavimentos. Este valor é respaldado pela norma DIN 5034 (DEUTSCHES..., 1997; ALUCCI, 2007), que indica utilizar 60\% de luz natural em relação à iluminação recomendada. Como a NBR 15575-1 (ABNT, 2008) indica que para salas e quartos deve-se utilizar no mínimo 100 lux de iluminação, consequentemente se tem o mínimo de 60 lux para iluminação natural;

(b) autonomia de luz natural (daylight autonomy - DA): indica a porcentagem de horas em que o nível de iluminância de projeto é atendido durante o período de um ano (REINHART;

MARDALJEVIC; ROGERS, 2006). Foram utilizados nas simulações os DA de $80 \%$ e $70 \%$ combinados com a ocorrência dos níveis de iluminância de projeto de 100 lux e 60 lux. Esses percentuais foram definidos em função da dificuldade de obter-se $100 \%$ de autonomia de luz natural no ambiente;

(c) autonomia espacial da luz natural: área do ambiente que deve apresentar DA igual ou acima do definido. Foi inicialmente utilizada a autonomia espacial de $100 \%$. Após a verificação da aplicabilidade em ambientes reais, foram testados os valores de $70 \%$ e de $50 \%$;

(d) horário de ocupação: horário em que a simulação computará os níveis de luz natural. O primeiro horário utilizado foi das $6 \mathrm{~h}$ às $18 \mathrm{~h}$, 
considerando um período médio aproximado de horas de sol no Brasil. O segundo horário simulado foi uma adequação às horas de sol de cada localidade avaliada. Para isso, por meio da análise da carta solar, determinou-se que seriam consideradas a partir de uma hora após o nascer do sol até uma hora antes do pôr do sol, durante o solstício de inverno (período mais curto de sol para cada cidade). Esse horário de ocupação foi denominado "horário variável", conforme a Tabela 2. O terceiro horário de ocupação utilizado foi das $8 \mathrm{~h}$ às $16 \mathrm{~h}$, que corresponde ao menor horário de ocupação utilizado no horário de ocupação variável; e

(e) latitude e orientação: para analisar o comportamento da luz natural diante das diferentes latitudes, foram realizadas simulações em 11 cidades. A escolha das cidades priorizou as capitais brasileiras de diferentes latitudes e com quatro diferentes zonas bioclimáticas (ZB). Assim, as cidades selecionadas foram: São Luís ( $3^{\circ} 21^{\text {' }}$

Sul, ZB 8); Natal (547' Sul, ZB 8); Maceió ( $9^{\circ} 21^{\prime}$ Sul, ZB 8); Salvador (1258’ Sul, ZB 8); Brasília (1555’ Sul, ZB 4); Belo Horizonte (196' Sul, ZB
3); Rio de Janeiro (1955' Sul, ZB3); São Paulo (2332' Sul, ZB3); Curitiba (2525' Sul, ZB 1); Florianópolis (270 $10^{\prime}$ Sul, ZB 3); e Porto Alegre (30 Sul, ZB 3).

Todas as condições simuladas foram realizadas para as orientações norte, sul, leste e oeste, tornando possível a análise da influência da orientação na profundidade-limite do ambiente.

\section{Modelo-base e combinação de variáveis (1a etapa de simulação)}

Para avaliar o comportamento da luz natural e verificar a profundidade de penetração da luz natural no ambiente, foi necessário verificar em diversas combinações as variáveis descritas anteriormente. Portanto, a partir do modelo-base, as variáveis iluminância de projeto, autonomia de luz natural e horário de ocupação foram combinadas em cinco diferentes situações (Tabela 3), simuladas para diversas latitudes e nas orientações norte, sul, leste e oeste, resultando na $1^{\text {a }}$ etapa de simulação, conforme apresentado no Quadro 2.

Tabela 2 - Horário de ocupação variável

\begin{tabular}{l|c|c|c|c|c}
\hline \multirow{2}{*}{ Cidade } & \multirow{2}{*}{ Latitude } & \multicolumn{2}{|c|}{ Solstício de inverno } & \multicolumn{2}{c}{$\begin{array}{c}\text { Horário utilizado } \\
\text { nas simulações }\end{array}$} \\
\cline { 3 - 6 } & & Nasce às & Põe-se às & De & Até \\
\hline São Luís & $03^{\circ} 21^{\prime}$ & $06 \mathrm{~h} 00$ & $18 \mathrm{~h} 00$ & $07 \mathrm{~h} 00$ & $17 \mathrm{~h} 00$ \\
Natal & $05^{\circ} 47^{\prime}$ & $06 \mathrm{~h} 00$ & $18 \mathrm{~h} 00$ & $07 \mathrm{~h} 00$ & $17 \mathrm{~h} 00$ \\
Maceió & $09^{\circ} 21^{\prime}$ & $06 \mathrm{~h} 15$ & $17 \mathrm{~h} 45$ & $07 \mathrm{~h} 15$ & $16 \mathrm{~h} 45$ \\
Slavador & $12^{\circ} 58^{\prime}$ & $06 \mathrm{~h} 15$ & $17 \mathrm{~h} 45$ & $07 \mathrm{~h} 15$ & $16 \mathrm{~h} 45$ \\
Brasília & $15^{\circ} 55^{\prime}$ & $06 \mathrm{~h} 30$ & $17 \mathrm{~h} 30$ & $07 \mathrm{~h} 30$ & $16 \mathrm{~h} 30$ \\
Belo Horizonte & $19^{\circ} 55^{\prime}$ & $06 \mathrm{~h} 45$ & $17 \mathrm{~h} 15$ & $07 \mathrm{~h} 45$ & $16 \mathrm{~h} 15$ \\
Rio de Janeiro & $22^{\circ} 54^{\prime}$ & $06 \mathrm{~h} 45$ & $17 \mathrm{~h} 15$ & $07 \mathrm{~h} 45$ & $16 \mathrm{~h} 15$ \\
São Paulo & $23^{\circ} 32^{\prime}$ & $06 \mathrm{~h} 45$ & $17 \mathrm{~h} 15$ & $07 \mathrm{~h} 45$ & $16 \mathrm{~h} 15$ \\
Curitiba & $25^{\circ} 25^{\prime}$ & $06 \mathrm{~h} 45$ & $17 \mathrm{~h} 15$ & $07 \mathrm{~h} 45$ & $16 \mathrm{~h} 15$ \\
Florianópolis & $2710^{\prime}$ & $07 \mathrm{~h} 00$ & $17 \mathrm{~h} 00$ & $08 \mathrm{~h} 00$ & $16 \mathrm{~h} 00$ \\
Porto Alegre & $30^{\circ} 01^{\prime}$ & $07 \mathrm{~h} 00$ & $17 \mathrm{~h} 00$ & $08 \mathrm{~h} 00$ & $16 \mathrm{~h} 00$ \\
\hline
\end{tabular}

Tabela 3 - Resumo das variáveis analisadas nas simulações com o modelo-base

\begin{tabular}{l|l}
\hline Iluminância de projeto & 100 lux \\
& 60 lux \\
\hline Autonomia de & $80 \%$ \\
iluminação natural & $70 \%$ \\
\hline \multirow{3}{*}{ Horário de ocupação } & $8 \mathrm{~h}$ às $18 \mathrm{~h}$ \\
& 8h às $16 \mathrm{~h}$ \\
& Horário variável \\
\hline \multirow{2}{*}{ Latitude } & 11 Latitudes $\left(3^{\circ} 21^{\prime}, 5^{\circ} 47^{\prime}, 9^{\circ} 21^{\prime}, 12^{\circ} 58^{\prime}, 15^{\circ} 55^{\prime}\right.$, \\
\hline \multirow{3}{*}{ Orientação } & $\left.19^{\circ} 6^{\prime}, 19^{\circ} 55^{\prime}, 23^{\circ} 32^{\prime}, 25^{\circ} 25^{\prime}, 27^{\circ} 10^{\prime}, 30^{\circ}\right)$ \\
& Norte \\
& Sul \\
& Leste \\
& Oeste \\
\hline
\end{tabular}

42 Albuquerque, M. S. C.; Amorim, C. N. D. 


\begin{tabular}{|l|c|c|c|c|c|}
\hline SITUAÇão & SITUAÇÃo 1 & SITUAÇÃo 2 & SITUAÇÃo 3 & SITUAÇÃo 4 & SITUAÇÃo 5 \\
\hline IlumináveIS & $100 \mathrm{lux}$ & $100 \mathrm{lux}$ & $60 \mathrm{lux}$ & $60 \mathrm{lux}$ & $60 \mathrm{lux}$ \\
\hline Autonomia de projeto & $80 \%$ & $80 \%$ & $80 \%$ & $70 \%$ & $70 \%$ \\
\hline Horário ocupação & $6 \mathrm{~h}$ às $18 \mathrm{~h}$ & Variável & Variável & $8 \mathrm{~h}$ às $16 \mathrm{~h}$ & Variável \\
\hline Cidades simuladas & 11 cidades & 5 cidades & 11 cidades & 11 cidades & 11 cidades \\
\hline Orientação & $\begin{array}{c}\text { Norte, sul, } \\
\text { leste, oeste }\end{array}$ & $\begin{array}{c}\text { Norte, sul, } \\
\text { leste, oeste }\end{array}$ & $\begin{array}{c}\text { Norte, sul, } \\
\text { leste, oeste }\end{array}$ & $\begin{array}{c}\text { Norte, sul, } \\
\text { leste, oeste }\end{array}$ & $\begin{array}{c}\text { Norte, sul, } \\
\text { leste, oeste }\end{array}$ \\
\hline Total de simulações & 44 & 20 & 44 & 44 & 44 \\
\hline
\end{tabular}

Quadro 2 - Modelo-base e combinação das variáveis - situação 1, 2, 3, 4 e 5 (1ª etapa de simulação)

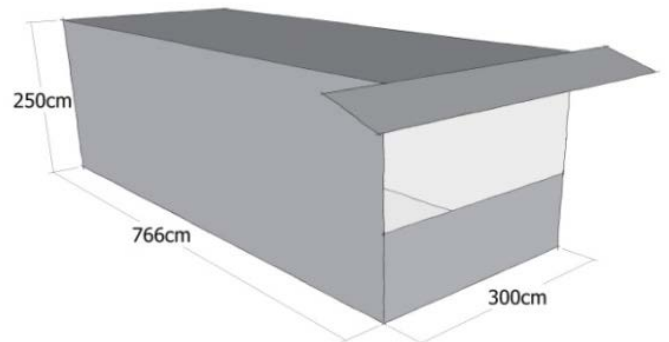

Figura 3 - Imagem do modelo 1

A combinação dessas variáveis resultou em 196 simulações, que objetivaram investigar o desempenho mínimo para iluminação natural e a profundidade máxima dos ambientes, relacionando-a com a altura da verga da janela, para garantir o desempenho mínimo.

\section{Desenvolvimento dos modelos 1, 2 e 3 (2a etapa de simulação)}

A segunda etapa teve como objetivo principal verificar a influência das proteções solares no alcance de profundidade da luz natural no ambiente. Para isso, foram desenvolvidos três modelos, utilizando as mesmas características de dimensões, formato, abertura, refletâncias e variáveis de simulação da situação 5, acrescentando um tipo de proteção solar diferente em cada um deles.

Esses modelos foram simulados nas orientações norte, sul, leste e oeste, para cinco cidades: São Luís (258’ Sul), Maceió (951’ Sul), Brasília (158' Sul), Curitiba (2551' Sul) e Porto Alegre $\left(30^{\circ}\right)$.

\section{Modelo 1}

Optou-se por representar edificações que possuem beirais como proteção solar, comuns em edificações residenciais unifamiliares.

Para verificar a influência desse tipo de proteção no comportamento da luz natural no ambiente, foi utilizada a proteção solar na horizontal acima da abertura (Figura 3), com três variações de dimensão: modelo 1a (beiral de $70 \mathrm{~cm}$ ), gerando um ângulo vertical de sombreamento de $29^{\circ}$; modelo $1 \mathrm{~b}$ (beiral de $100 \mathrm{~cm}$ ), com ângulo vertical de sombreamento de $38^{\circ}$; e modelo $1 c$ (beiral de $120 \mathrm{~cm}$ ), com um ângulo vertical de $43^{\circ}$.

Os beirais das três variações do modelo 1 foram modelados com superfícies de refletância de 30\%, equivalente à refletância das telhas de barro, entre 0,35 e 0,20 .

\section{Modelo 2}

O modelo 2 representa edificações que possuem proteções verticais geradas pelo autossombreamento da fachada, comumente encontrado em edificações residenciais, onde as aberturas localizam-se em recuos da fachada, que promovem sombreamento nas aberturas, como pode ser observado na Figura 4.

Para verificar a influência desse tipo de proteção no comportamento da luz natural no ambiente interno, foi utilizada proteção solar vertical nas duas laterais da abertura (Figura 5), com três variações de dimensão: modelos 2a, 2b e 2c.

Os modelos 2a, 2b e 2c possuem duas proteções verticais de $50 \mathrm{~cm}, 80 \mathrm{~cm}$ e $120 \mathrm{~cm}$, gerando dois ângulos horizontais de sombreamento, de $9^{\circ}, 15^{\circ} \mathrm{e}$ $22^{\circ}$ em cada lado da abertura respectivamente. A refletância dessas proteções, nas três variações do modelo 2 , foi de $58 \%$. 


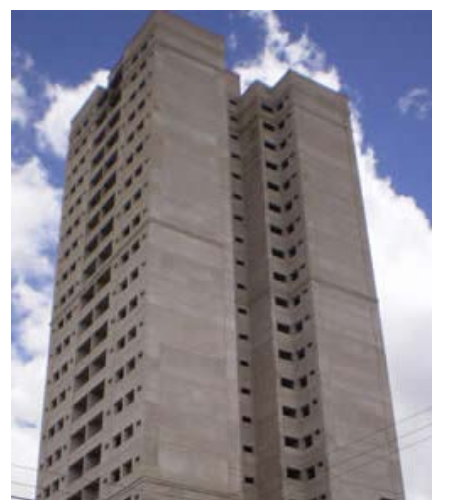

Figura 4 - Edifício com proteção vertical, formada pelo recuo da fachada

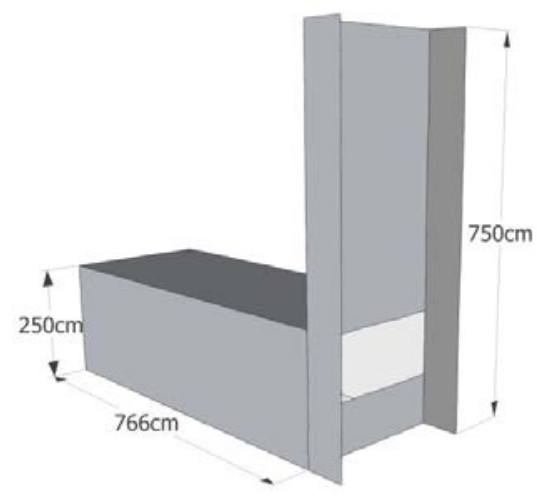

Figura 5 - Imagem do modelo 2

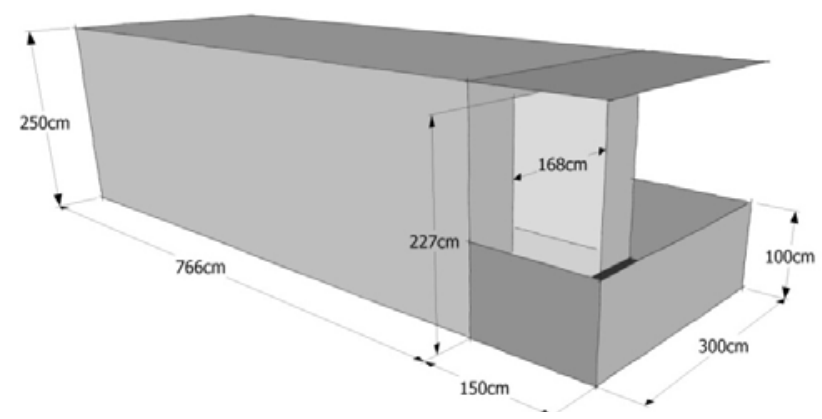

Figura 6 - Imagem do modelo 3

\section{Modelo 3}

Representa as proteções horizontais geradas por varandas (Figura 6). As varandas promovem sombreamento vertical das aberturas, além do sombreamento gerado pelo peitoril.

O modelo foi construído a partir do modelo-base, no entanto as dimensões da abertura foram modificadas para configurar uma porta, tendo em vista o uso da varanda. Para garantir a mesma área de abertura do modelo-base, de $3,83 \mathrm{~m}^{2}$, as dimensões da abertura do modelo 3 são 2,27 m de altura (permaneceu a altura da verga da janela) e 1,68 m de largura. A varanda inserida foi de 1,50 $\mathrm{m}$ de profundidade, gerando um ângulo vertical de sombreamento de $31^{\circ}$.

As refletâncias das superfícies da varanda são:
(a) piso com refletância de $30 \%$;
(b) peitoril, 58\% de refletância; e
(c) teto, refletância de $84 \%$.

A Tabela 4 resume as características dos modelos 1 , 2 e 3.

44 Albuquerque, M. S. C.; Amorim, C. N. D. 
Tabela 4 - Tabela resumo dos modelos 1, 2 e 3

\begin{tabular}{|c|c|c|c|c|c|c|c|c|}
\hline \multirow{2}{*}{\multicolumn{2}{|c|}{ Tipo de proteção }} & \multicolumn{3}{|c|}{ MODELO 1} & \multicolumn{3}{|c|}{ MODELO 2} & \multirow{2}{*}{$\begin{array}{c}\text { MODELO } 3 \\
\text { Mista - tipo } \\
\text { varanda } \\
\end{array}$} \\
\hline & & \multicolumn{3}{|c|}{ Horizontal - tipo beiral } & \multicolumn{3}{|c|}{ Vertical - tipo recuo } & \\
\hline \multicolumn{2}{|c|}{ Viariações do modelo } & $1 \mathrm{a}$ & $1 b$ & $1 c$ & $1 \mathrm{a}$ & $1 b$ & 1c & - \\
\hline \multicolumn{2}{|c|}{ Dimensão da proteção } & $70 \mathrm{~cm}$ & $100 \mathrm{~cm}$ & $120 \mathrm{~cm}$ & $50 \mathrm{~cm}$ & $80 \mathrm{~cm}$ & $120 \mathrm{~cm}$ & $150 \mathrm{~cm}$ \\
\hline \multirow{5}{*}{ 氖 } & $\begin{array}{l}\text { Iluminância de } \\
\text { projeto }\end{array}$ & \multicolumn{7}{|c|}{$60 \operatorname{lux}$} \\
\hline & $\begin{array}{l}\text { Autonomia de } \\
\text { luz natural }\end{array}$ & \multicolumn{7}{|c|}{$70 \%$} \\
\hline & $\begin{array}{l}\text { Horário de } \\
\text { ocupação }\end{array}$ & \multicolumn{7}{|c|}{ Variável } \\
\hline & $\begin{array}{l}\text { Cidades } \\
\text { Simuladas }\end{array}$ & \multicolumn{7}{|c|}{5 cidades } \\
\hline & Orientação & \multicolumn{7}{|c|}{ Norte, sul, leste, oeste } \\
\hline \multicolumn{2}{|c|}{ Total de simulações } & 20 & 20 & 20 & 20 & 20 & 20 & 20 \\
\hline
\end{tabular}

\section{Simulação}

Para iniciar as simulações é necessário importar para o Software Daysim os modelos tridimensionais construídos e caracterizados no programa Sketchup, além da malha de pontos de medição do ambiente. Em seguida, são configurados os parâmetros da simulação, que guiam o programa sobre como realizar essa simulação (REINHART, 2010).

Após cada simulação, o Daysim produz um relatório com valores em medidas para análise da luz natural para cada ponto da malha de medição. As medidas fornecidas são as seguintes: fator de luz natural (DF), autonomia de luz natural (DA), autonomia de luz natural contínua (DAcon), autonomia de luz natural máxima (DAmax), iluminância natural útil (UDI) e a exposição anual de luz. A medida utilizada nesta pesquisa foi DA, que indica em porcentagem as horas do ano em que determinada iluminância (iluminância de projeto) é atendida apenas com a luz natural.

O Daysim importa dois tipos de formato de arquivos climáticos que contêm o TRY, os arquivos .epw e .wea, e extrai as informações necessárias para a simulação (REINHART, 2010). Neste trabalho, foram utilizados os arquivos climáticos de cidades brasileiras, disponibilizados pelo Laboratório de Eficiência Energética em Edificações (LabEEE) da UFSC.

\section{Processamento e análise dos dados}

Para a análise da profundidade alcançada pela luz natural no ambiente, foi utilizada parte da metodologia desenvolvida por Didoné (2009).

Após as simulações, o relatório gerado pelo Daysim fornece os valores de DA em cada ponto da malha de medição. Esses dados foram inseridos no programa WinSurf, que converte tabela de dados em curvas de cores falsas com mesmo DA (ISO-DA) (Figura 7). Com o gráfico gerado é possível analisar o comportamento da luz natural no ambiente através da visualização das diferentes faixas de valores de DA distribuídos pelo plano de trabalho. Em seguida, os gráficos gerados no WinSurf são exportados na extensão .jpg e inseridos no AutoCAD 2009, sobrepostos à planta baixa do ambiente. Dessa forma, é possível analisar o comportamento da luz natural em conjunto com os limites do ambiente e faz-se a medição da profundidade atingida por determinada curva de ISO-DA.

No arquivo CAD, a profundidade alcançada pela luz natural (PLN, em metros) foi medida até a extensão que atingiu as condições exigidas. Em seguida esse valor foi relacionado à altura da verga da janela. Assim, as medições da profundidade foram feitas na planta do arquivo CAD e divididas por 2,27 m (altura da verga da janela de todos os modelos). Ou seja, a relação de profundidade (P) é igual à profundidade atingida pela luz natural mantendo a iluminância de projeto previamente definida, dividida pela altura da verga da janela, conforme a Equação 1 abaixo:

$\mathrm{P}=\mathrm{PLN} / \mathrm{H}$

Eq. 1

Onde:

$\mathrm{P}=$ relação da profundidade da luz natural com a altura da verga da janela (adimensional);

PLN = profundidade alcançada no ambiente pela luz natural com a iluminância de projeto e DA definidas (metros); e

$\mathrm{H}=$ altura da verga da janela (2,27 $\mathrm{m}$ em todos os modelos). 


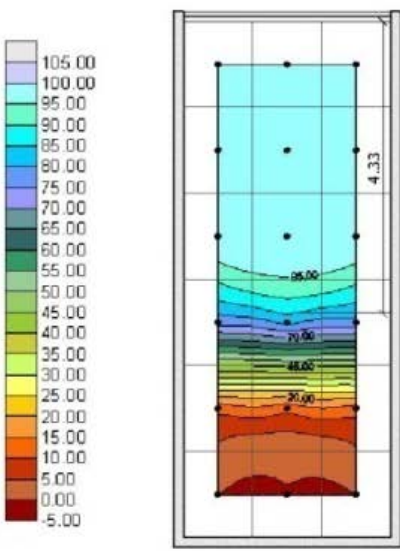

Norte
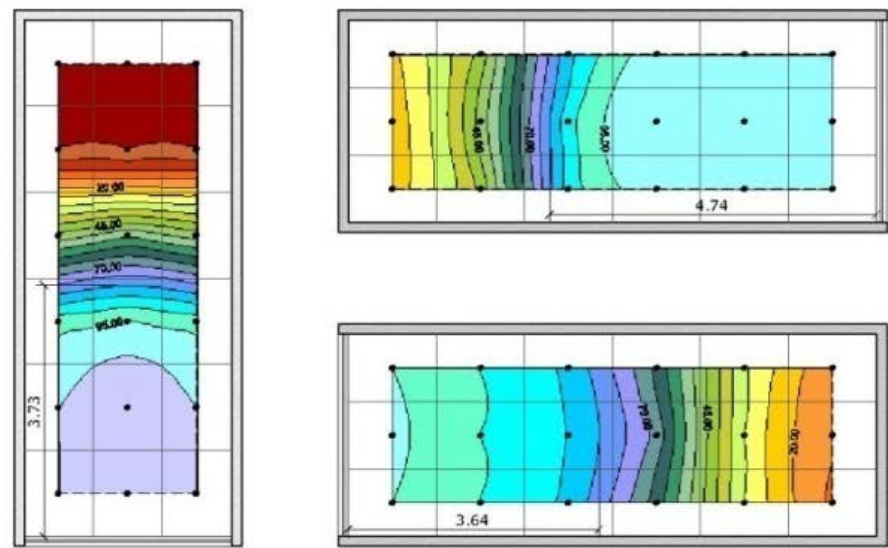

Leste

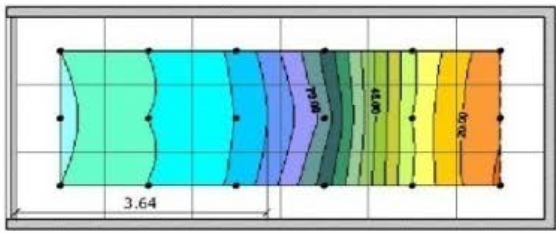

Oeste

Figura 7 - Exemplo de gráficos de ISO-DA integrados à planta baixa do ambiente

Nota: as faixas de cores representam em porcentagem as horas do ano, com determinado horário de ocupação, que atendem à iluminância de projeto.

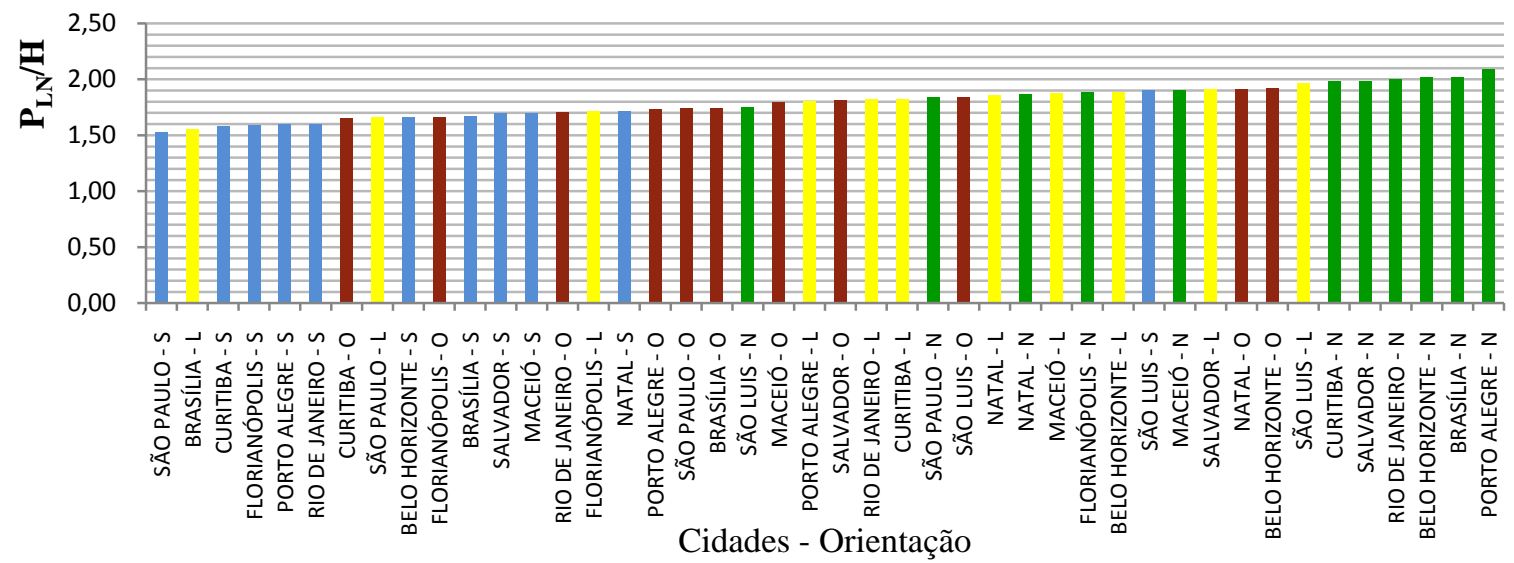

Figura 8 - Modelo 5: 60 lux, variável e 70\%

A profundidade alcançada pela luz natural em cada modelo é identificada, e os dados sintetizados em formato de gráficos, gerados pelo Microsoft Excel. A partir dos gráficos gerados é possível a comparação dos resultados entre várias latitudes e orientações, conforme exemplifica a Figura 8.

\section{Verificação da aplicabilidade em casos reais}

Depois de identificados os valores do limite da profundidade do ambiente em relação à altura da verga da janela para ambientes com e sem proteção solar, verificou-se a aplicabilidade deles em ambientes de edificações residenciais reais localizadas nas cidades de Florianópolis e Brasília. Para isso, foi verificada a relação da profundidade com a altura da verga da janela em 20 ambientes sem proteção solar e em 20 ambientes com proteção solar.

Para tanto, foram definidas as seguintes condições: (a) em ambientes com mais de uma abertura em paredes diferentes, mas com superfície única de profundidade, foi considerada a menor profundidade;

(b) em ambientes com aberturas de alturas diferentes, na mesma fachada, foi utilizada a média das alturas; e

(c) em ambientes com aberturas em uma fachada que possuem profundidade com superfícies de distâncias diferentes em relação às aberturas, foi considerada a maior distância.

\section{Resultados da primeira etapa de simulações (modelo-base sem proteção solar)}

A Tabela 5 apresenta o resumo dos resultados da $1^{\text {a }}$ etapa de simulações (modelo-base nas situações de 1 a 5) quanto à profundidade alcançada pela luz natural em relação à altura da verga da janela,

46 Albuquerque, M. S. C.; Amorim, C. N. D. 
considerando as variáveis iluminância de projeto, horário de ocupação, autonomia de luz natural, orientação e latitude.

A iluminância de projeto de 100 lux, utilizada nas situações 1 e 2, resultou em um pequeno alcance da profundidade no ambiente (Tabela 5), apesar de ser um valor relativamente baixo para iluminância em ambientes residenciais. A utilização da iluminância de projeto de 60 lux aparece como uma alternativa em consonância com a NBR 15575-1 (ABNT, 2008).

O horário de ocupação influencia muito nos resultados. Observa-se na Tabela 6 que apenas na situação 1 , que utilizou o horário das $6 \mathrm{~h}$ às $18 \mathrm{~h}$, houve um comportamento diferente da luz natural em relação às demais situações. Nesse caso, as orientações leste e oeste obtiveram os maiores resultados, e não a orientação norte. Isso ocorre porque as cidades de menor latitude possuem horas de sol praticamente constantes ao longo do ano, com o nascer próximo das 6h e por do sol próximo das 18h. Já nas cidades com maior latitude, as horas de sol são bem menores no período de inverno, ocorrendo contagem, nos resultados, de horas em que ainda não há luz natural. E no verão, quando o período em que há luz natural é maior, o limite até as $18 \mathrm{~h}$ impede a contagem após esse horário.

Nas demais situações, os maiores resultados foram para a orientação norte; os valores intermediários, para as orientações leste e oeste; e os menores valores foram para a orientação sul. Esse comportamento responde à maior incidência de luz solar direta na fachada norte durante o período de um dia, principalmente nas maiores latitudes, enquanto as orientações leste e oeste recebem luz direta apenas em um período do dia. A fachada com orientação sul é a que recebe menos luz direta, principalmente nas maiores latitudes, por isso os menores valores de profundidade.

\section{Tabela 5 - Resumo dos resultados para os Modelos sem proteção solar (1a Etapa de Simulação)}

\begin{tabular}{|c|c|c|c|c|c|c|}
\hline \multicolumn{2}{|c|}{$\begin{array}{c}1 \text { Modelo-base } \\
2 \text { (sem proteção solar) }\end{array}$} & Situação 1 & Situação 2 & Situação 3 & Situação 4 & Situação 5 \\
\hline \multirow{3}{*}{ Variáveis } & $\begin{array}{l}\text { Iluminância } \\
\text { de projeto }\end{array}$ & $100 \operatorname{lux}$ & $100 \operatorname{lux}$ & 60 lux & & \\
\hline & $\mathrm{DA}$ & $80 \%$ & $80 \%$ & $80 \%$ & & \\
\hline & $\begin{array}{l}\text { Horário da } \\
\text { ocupação }\end{array}$ & $6 \mathrm{~h}$ às $18 \mathrm{~h}$ & Variável & Variável & & \\
\hline \multirow{3}{*}{$\begin{array}{l}\text { Profundidade } \\
\text { da luz } \\
\text { natural em } \\
\text { relação à } \\
\text { altura da } \\
\text { verga da } \\
\text { janela }\end{array}$} & Menor valor & 0,81 & 1,0 & 1,41 & 1,57 & 1,53 \\
\hline & Maior valor & 1,14 & 1,43 & 2,0 & 2,11 & 2,09 \\
\hline & Média & 0,96 & 1,26 & 1,65 & 1,86 & 1,8 \\
\hline \multirow{3}{*}{ Orientação } & $\begin{array}{l}\text { Orientação } \\
\text { que obteve os } \\
\text { maiores } \\
\text { valores }\end{array}$ & Leste & Norte & Norte & Norte & Norte \\
\hline & $\begin{array}{l}\text { Orientação } \\
\text { que obteve os } \\
\text { valores } \\
\text { intermediário }\end{array}$ & $\begin{array}{l}\text { Oeste e } \\
\text { norte }\end{array}$ & $\begin{array}{l}\text { Leste e } \\
\text { oeste }\end{array}$ & $\begin{array}{l}\text { Leste e } \\
\text { oeste }\end{array}$ & $\begin{array}{l}\text { Leste e } \\
\text { oeste }\end{array}$ & $\begin{array}{l}\text { Leste e } \\
\text { oeste }\end{array}$ \\
\hline & $\begin{array}{l}\text { Orientação } \\
\text { que obteve os } \\
\text { menores } \\
\text { valores }\end{array}$ & Sul & Sul & Sul & Sul & Sul \\
\hline \multirow{2}{*}{ Latitude } & $\begin{array}{l}\text { Tendência da } \\
\text { latitude para } \\
\text { os maiores } \\
\text { valores }\end{array}$ & $\begin{array}{l}\text { Menores } \\
\text { latitudes }\end{array}$ & $\begin{array}{l}\text { Maiores } \\
\text { latitudes }\end{array}$ & $\begin{array}{l}\text { Maiores } \\
\text { latitudes }\end{array}$ & $\begin{array}{l}\text { Maiores } \\
\text { latitudes }\end{array}$ & $\begin{array}{l}\text { Maiores } \\
\text { latitudes }\end{array}$ \\
\hline & $\begin{array}{l}\text { Tendência da } \\
\text { latitude para } \\
\text { os menores } \\
\text { valores }\end{array}$ & $\begin{array}{l}\text { Maiores } \\
\text { valores }\end{array}$ & $\begin{array}{l}\text { Maiores } \\
\text { valores }\end{array}$ & $\begin{array}{l}\text { Maiores } \\
\text { valores }\end{array}$ & $\begin{array}{l}\text { Maiores } \\
\text { valores }\end{array}$ & $\begin{array}{l}\text { Maiores } \\
\text { valores }\end{array}$ \\
\hline
\end{tabular}


Pode-se verificar pela Tabela 6 que a utilização do menor horário de ocupação, na situação 4, também influenciou na obtenção dos maiores resultados de profundidade. No entanto, o horário variável para cada latitude pareceu ser o mais coerente, tendo em vista que os resultados refletem as características de horas de sol de cada cidade, sem prejudicar ou beneficiar os resultados para cidades de latitudes diferentes.

Quanto à autonomia de luz natural (DA), observou-se que o DA de $80 \%$ é uma porcentagem elevada para ser exigida, tendo em vista que a profundidade alcançada nas situações 1 e 2 foi apenas de 0,96 e de 1,26 vez a altura da verga da janela respectivamente. E quando diminuída a iluminância de projeto para 60 lux, mantendo-se o DA de $80 \%$ (situação 3), obtiveram-se resultados de profundidade de apenas 1,65 vez a altura da janela. Nota-se que nas três situações em que se utilizou o DA de $80 \%$ os resultados apresentaramse distantes do indicado pela literatura - entre 1,5 e 2,5 vezes a altura da verga da janela (REINHART, 2005) - e, por isso, decidiu-se reduzir o valor de DA para $70 \%$ nas demais simulações.

A orientação também interferiu significativamente nos resultados alcançados, principalmente nas cidades de maior latitude (Figuras 9, 10, 11, 12 e 13). Apesar de haver diferença na profundidade alcançada pela luz natural para cada orientação em todas as cidades simuladas, nas localidades com menor latitude a diferença de uma orientação para outra é pequena quando comparada com as cidades de maior latitude.

A orientação norte obteve os maiores resultados na profundidade, exceto na situação 1. Fachadas voltadas para a orientação norte são as que recebem a maior incidência solar no contexto brasileiro, principalmente nas maiores latitudes. No entanto, na situação 1 os maiores valores foram na orientação leste para as cidades de menor latitude, enquanto a orientação norte obteve os valores intermediários. Isso ocorreu em decorrência do horário de ocupação utilizado na situação 1 , das 6 h às $18 \mathrm{~h}$, que coincide com 0 horário de sol de cidades de menor latitude (onde o nascer do sol é próximo das 6h, e o por do sol, próximo das $18 \mathrm{~h})$. Nesta situação, as cidades de maiores latitudes no verão não tiveram computadas as horas “a mais” de luz natural, e no inverno, são computadas horas em que não há luz natural.

Já a orientação sul obteve os menores valores em todas as situações (Figura 19). As orientações leste e oeste obtiveram, na maioria dos casos, valores intermediários, sendo que em todos os modelos a média da orientação leste foi um pouco maior em relação à orientação oeste. A Figura 19 apresenta a comparação da média da profundidade alcançada pela luz natural com relação à altura da verga da janela por orientação, em todas as situações simuladas.

Quanto maior a latitude, maior é a incidência solar na fachada norte e menor é a incidência solar na fachada sul; por este motivo, identificou-se nos resultados que, quanto maior a latitude, maiores os resultados da profundidade alcançada pela luz natural na orientação norte e menores os resultados para orientação sul. Essa característica de resultados é verificada nas situações 3,4 e 5 através das Figuras 11, 12 e 13, que indicam os resultados de cada orientação por latitude.

\section{Comparação da média da profundidade por orientação}

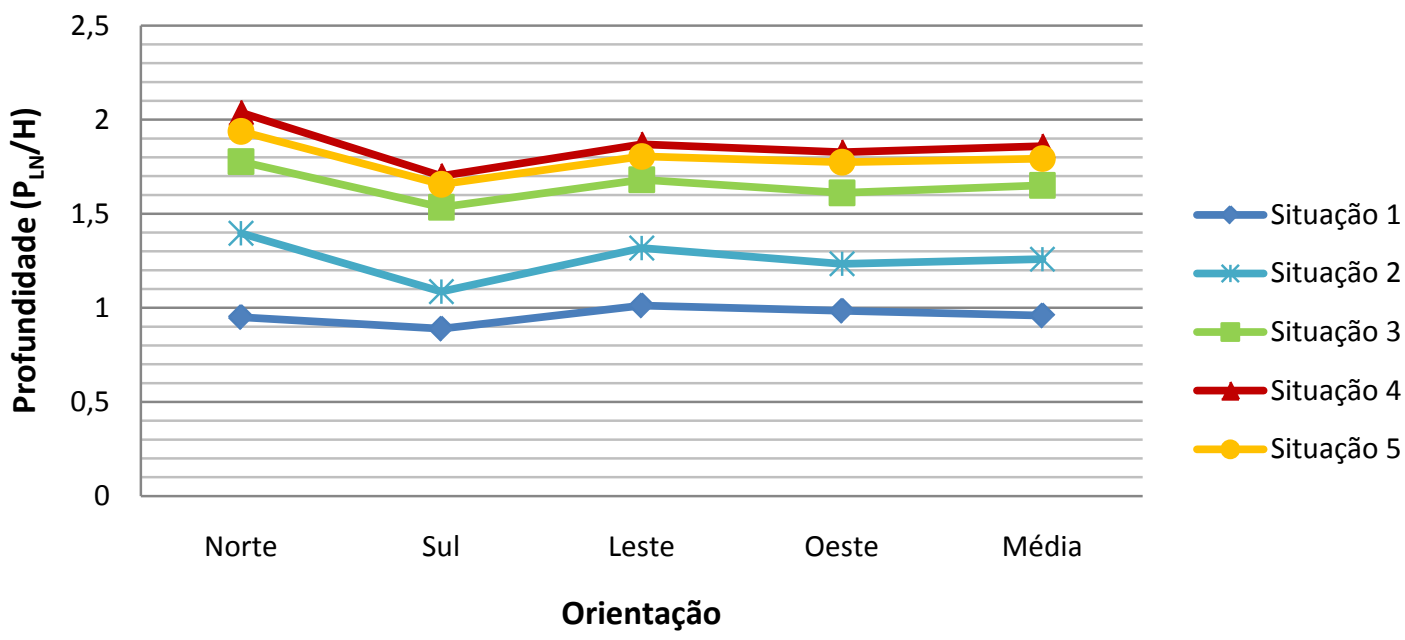

Figura 9 - Comparação das médias da profundidade por orientação em cada situação 


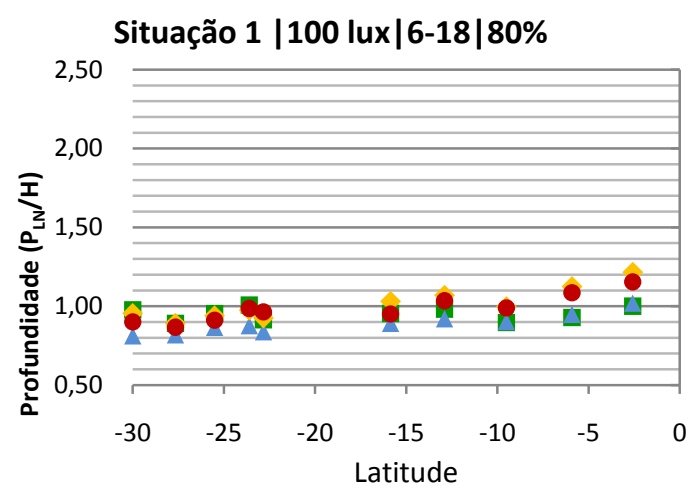

Figura 10 - Resultados da situação 1

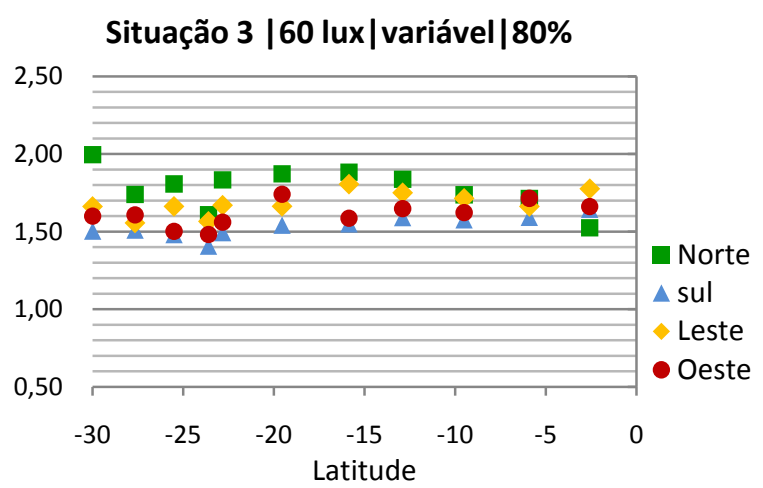

Figura 11 - Resultados da situação 3

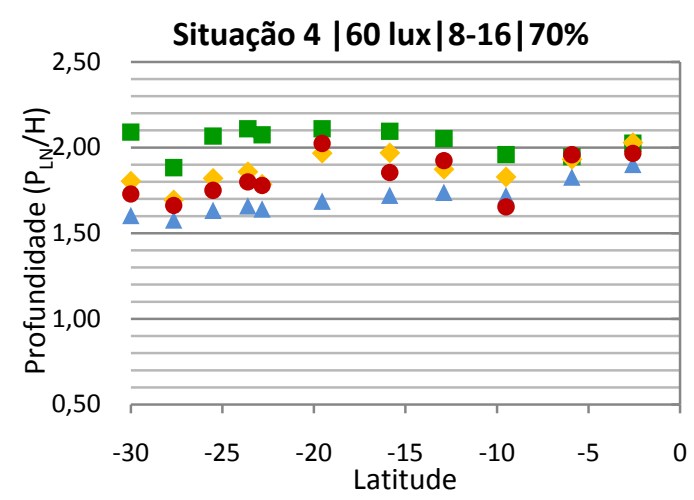

Figura 12 - Resultados da situação 4

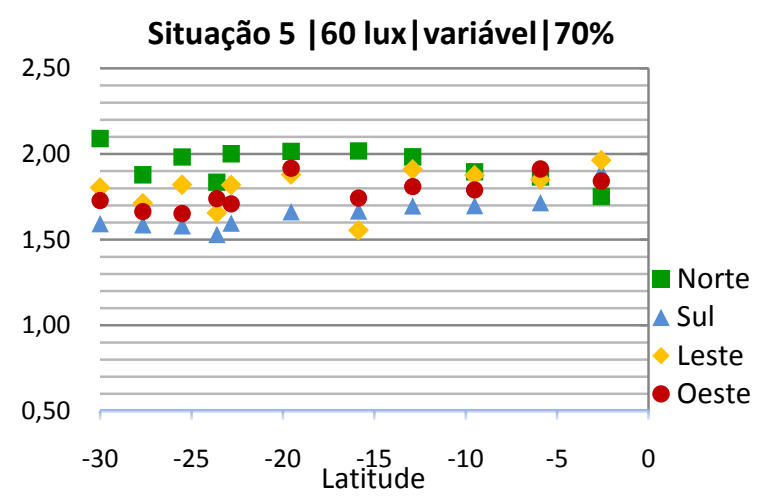

Figura 13 - Resultados da situação 5 
A situação 5 utilizou a iluminância recomendada pela NBR 15575, de 60 lux para iluminância de projeto, com uma autonomia de luz natural de $70 \%$ das horas e o horário de ocupação de acordo com o horário de sol de cada cidade. Esta obteve o resultado da relação entre a profundidade-limite do ambiente e 1,80 vez a altura da verga da janela, próximo aos valores apresentados na literatura (REINHART, 2005; VIANNA; GONÇALVES, 2007).

O valor encontrado na situação 5 indica que ambientes em edificações localizadas no Brasil, nas orientações norte, sul, leste ou oeste, com área de abertura em torno de 1/6 da área de piso, sem proteção solar e com refletâncias internas no padrão utilizado na arquitetura, devem ter uma profundidade limite de 1,8 vez a altura da verga da janela para obter 60 lux em todo o ambiente, em $70 \%$ das horas do ano, de acordo com o horário de sol de cada localidade.

Portanto, a situação 5 aparece com os resultados mais coerentes para definir o desempenho mínimo da luz natural no ambiente (60 lux em 70\% das horas do ano, considerando o horário de sol de cada cidade) e o limite da profundidade de ambientes sem proteção solar de 1,8 vez a altura da verga da janela, para as cidades brasileiras.

\section{Verificação de aplicabilidade do resultado (1 1 etapa)}

Para verificar a aplicabilidade em ambientes reais do valor identificado para profundidade-limite do ambiente (1,8 vez a altura da janela), foi avaliada a profundidade de 20 ambientes reais, sendo 8 deles de edificações localizadas em Florianópolis e 12 em Brasília (Tabela 6). Destaca-se que os ambientes selecionados não possuem nenhum tipo de proteção solar nas aberturas e não é conhecida a refletância das paredes. Esse processo foi realizado conforme o exemplo da Figura 14.

Ao verificar a relação da profundidade dos 20 ambientes selecionados com a altura de sua respectiva janela, verificou-se que apenas 55\% deles atenderam ao limite da profundidade de 1,8 vez a altura da verga da janela. Essa porcentagem foi considerada pequena para o total da amostra, sendo, portanto, pouco aplicável à realidade das edificações residenciais. Visto que na primeira versão do RTQ-R, o objetivo era garantir sua aplicabilidade em número razoável de edificações, decidiu-se reduzir a autonomia espacial da luz natural, de 100\% para 70\%. Essa redução baseouse também na recomendação da Certificação LEED $^{1}$ (Orientação para Projetos de Arquitetura), que indica que "pelo menos $75 \%$ de todas as áreas de ambientes regularmente ocupados” devem atingir um nível mínimo de iluminação natural ${ }^{2}$. No caso presente, foi adotada a exigência de $70 \%$, ou seja, o ambiente deve garantir 60 lux em $70 \%$ do ambiente durante $70 \%$ das horas do ano em que possui luz natural (horário variável). Com essa correção, o valor-limite da profundidade do ambiente passou para 2,57 vezes a altura da verga da janela.

Da mesma forma, verificou-se nos 20 ambientes a aplicabilidade do valor da profundidade-limite com o DA espacial de $70 \%$. O resultado foi que $100 \%$ dos ambientes atenderam ao limite da profundidade de 2,57 vezes a altura da verga da janela. Essa porcentagem foi considerada satisfatória, permitindo a aplicação em casos reais.

Localização: Brasília

Profundidade: $4,37 \mathrm{~m}$

Dimensões da abertura: 1,2 m x 1,2 m

Peitoril: 1,06 m | Altura da abertura: 2,26 m

Aplicação do valor de 1,8:

$\mathrm{P} \leq 1,80 \times \mathrm{H}$ janela

$4,37 \mathrm{~m} \geq 4,07 \mathrm{~m}$-> Não atendeu

Aplicação do valor de 2,57:

$\mathrm{P} \leq 2,57 \times \mathrm{H}$ janela

4,37 $\mathrm{m} \leq 5,80 \mathrm{~m}->$ Atendeu

Figura 14 - Exemplo do processo da verificação da aplicabilidade do resultado

\footnotetext{
${ }^{1}$ Leadership in Energy and Environmental Design - certificação para edifícios sustentáveis, concebida e concedida pela ONG americana U.S. Green Building Council (USGBC).

${ }^{2}$ O LEED indica como nível mínimo de iluminação natural 270 lux , por se tratar de ambientes de escritórios.
} 
Tabela 6 - Tabela-resumo da verificação da aplicabilidade do resultado para ambientes sem proteção solar

\begin{tabular}{|c|c|c|c|c|c|c|}
\hline $\mathbf{N}^{\mathbf{0}}$ & Cidade & Ambiente & $\begin{array}{l}\text { Profundida } \\
\text { de ambiente }\end{array}$ & $\begin{array}{c}\text { Altura } \\
\text { janela }\end{array}$ & $\begin{array}{c}P \leq 1,80 \times H \\
\text { janela }\end{array}$ & $\begin{array}{c}P \leq 2,57 x \\
H \text { janela }\end{array}$ \\
\hline 1 & Florianópolis & Sala & 5,15 & 2,0 & Não atendeu & Atendeu \\
\hline 2 & Florianópolis & Quarto & 3,00 & 2,20 & Atendeu & Atendeu \\
\hline 3 & Florianópolis & Quarto & 4,40 & 2,20 & Não Atendeu & Atendeu \\
\hline 4 & Florianópolis & Quarto & 5,00 & 2,30 & Não Atendeu & Atendeu \\
\hline 5 & Florianópolis & Cozinha & 4,45 & 2,20 & Não Atendeu & Atendeu \\
\hline 6 & Florianópolis & Cozinha & 6,00 & 2,50 & Não Atendeu & Atendeu \\
\hline 7 & Florianópolis & Área serviço & 2,80 & 2,20 & Atendeu & Atendeu \\
\hline 8 & Florianópolis & Lavanderia & 4,00 & 2,50 & Atendeu & Atendeu \\
\hline 9 & Brasília & Quarto & 3,19 & 2,10 & Atendeu & Atendeu \\
\hline 10 & Brasília & Quarto & 3,00 & 3,50 & Atendeu & Atendeu \\
\hline 11 & Brasília & Sala & 2,88 & 2,30 & Atendeu & Atendeu \\
\hline 12 & Brasília & Sala & 6,27 & 2,50 & Não Atendeu & Atendeu \\
\hline 13 & Brasília & Quarto & 3,07 & 2,50 & Atendeu & Atendeu \\
\hline 14 & Brasília & Quarto & 3,95 & 2,50 & Atendeu & Atendeu \\
\hline 15 & Brasília & Cozinha & 4,73 & 2,10 & Não Atendeu & Atendeu \\
\hline 16 & Brasília & Quarto & 5,56 & 2,26 & Atendeu & Atendeu \\
\hline 17 & Brasília & Sala & 5,28 & 2,26 & Não Atendeu & Atendeu \\
\hline 18 & Brasília & Cozinha & 4,37 & 2,26 & Não Atendeu & Atendeu \\
\hline 19 & Brasília & Sala & 3,98 & 2,90 & Atendeu & Atendeu \\
\hline 20 & Brasília & Quarto & 4,55 & 2,90 & Atendeu & Atendeu \\
\hline
\end{tabular}

Tabela 7 - Resumo dos resultados dos modelos com proteção solar - 2a etapa de simulação

\begin{tabular}{|c|c|c|c|c|c|c|c|}
\hline & \multicolumn{3}{|c|}{ MODELO 1} & \multicolumn{3}{|c|}{ MODELO 2} & $\begin{array}{c}\text { MODELO } \\
3\end{array}$ \\
\hline $\begin{array}{l}\text { Tipo de } \\
\text { proteção }\end{array}$ & \multicolumn{3}{|c|}{ Horizontal - tipo beiral } & \multicolumn{3}{|c|}{ Vertical - tipo recuo } & $\begin{array}{c}\text { Mista - tipo } \\
\text { varanda }\end{array}$ \\
\hline $\begin{array}{l}\text { Variações do } \\
\text { modelo }\end{array}$ & $1 \mathrm{a}$ & $1 b$ & 1c & $1 \mathrm{a}$ & $1 b$ & 1c & - \\
\hline $\begin{array}{l}\text { dimensão da } \\
\text { proteção }\end{array}$ & $70 \mathrm{~cm}$ & $100 \mathrm{~cm}$ & $120 \mathrm{~cm}$ & $50 \mathrm{~cm}$ & $80 \mathrm{~cm}$ & $120 \mathrm{~cm}$ & $150 \mathrm{~cm}$ \\
\hline $\begin{array}{l}\text { Média da } \\
\text { profundidade } \\
\text { em relação à } \\
\text { altura da janela }\end{array}$ & 1,57 & 1,51 & 1,47 & 1,70 & 1,65 & 1,61 & 1,23 \\
\hline $\begin{array}{l}\text { Redução da } \\
\text { situação } 5 \text { para } \\
\text { a média do } \\
\text { modelo (em \%) }\end{array}$ & \multicolumn{3}{|c|}{$15,60 \%$} & \multicolumn{3}{|c|}{$8,02 \%$} & $30,07 \%$ \\
\hline $\begin{array}{l}\text { Redução da } \\
\text { situação } 5 \text { para } \\
\text { a média do } \\
\text { modelo (em \%) }\end{array}$ & \multicolumn{7}{|c|}{$17,90 \%$} \\
\hline
\end{tabular}

\section{2a Etapa de simulações (modelos com proteção solar)}

O objetivo da $2^{a}$ etapa foi verificar a influência de elementos de proteção solar das aberturas no comportamento da iluminação natural do ambiente interno, definindo, assim, o valor da profundidadelimite do ambiente em relação à altura da janela, para que sejam garantidas as mesmas condições de iluminação indicadas na situação 5.

Assim, segundo a metodologia descrita, foram analisados os três modelos com proteção solar, observando o comportamento da luz natural em relação à situação 5. A Tabela 7 contém o resumo das análises dos resultados quanto à profundidade alcançada pela luz natural em relação à altura da 
janela, e a redução da média dos modelos em relação à situação sem proteção - situação 5.

Verifica-se na Tabela 7 que o modelo 2 é o que apresentou a maior profundidade de penetração da luz natural, sendo a proteção vertical a que menos impactou na redução da profundidade em relação ao modelo sem proteção. Já as proteções do tipo beirais e varandas são as que mais influenciam nos resultados de iluminação natural no ambiente interno, tendo em vista que os modelos 1 e 3 foram os que apresentaram a maior redução da profundidade da luz natural no ambiente em comparação com a situação 5 . A média da redução da profundidade da luz natural provocada pela inserção de proteções solares foi de 17,90\%.

Tendo em vista que a profundidade-limite do ambiente sem proteção solar é de 2,57 vezes a altura da janela, em ambientes com proteção solar a profundidade alcançada pela luz natural para atender aproximadamente às mesmas condições reduz 17,90\%. Assim, a profundidade-limite de ambientes com proteção solar é de aproximadamente 2,11 vezes a altura da janela para obterem-se 60 lux (iluminância de projeto), em $70 \%$ das horas (DA), em $70 \%$ do espaço do ambiente (DA espacial).
A orientação influenciou o comportamento da profundidade alcançada pela luz natural nos modelos 1 e 2 de maneira similar à situação 5 , na qual os maiores valores de profundidade alcançada foram na orientação norte, os menores na orientação sul, e as orientações leste e oeste obtiveram valores intermediários. O modelo 3 , com proteção mista, foi o que provocou maior redução da profundidade de penetração da luz no ambiente e foi o único com proteção solar que apresentou um comportamento diferente dos demais, pois a orientação sul obteve o maior valor de profundidade, e a norte, o menor. Esse comportamento pode ser observado na Figura 15, que apresenta a média dos resultados por orientação dos modelos 1, 2, 3 e situação 5 .

Assim como nos modelos sem proteção solar, nos modelos 1, 2 e 3 a orientação influencia mais nos resultados para as cidades de maior latitude. Como pode ser observado nas Figuras 16, 17, 18 e 19, em todos os modelos na latitude $3^{\circ} 21^{\prime}$ (São Luís) os resultados de cada orientação ficam bastante próximos entre si, enquanto nas maiores latitudes aumenta a diferença entre as orientações dos valores obtidos da profundidade.

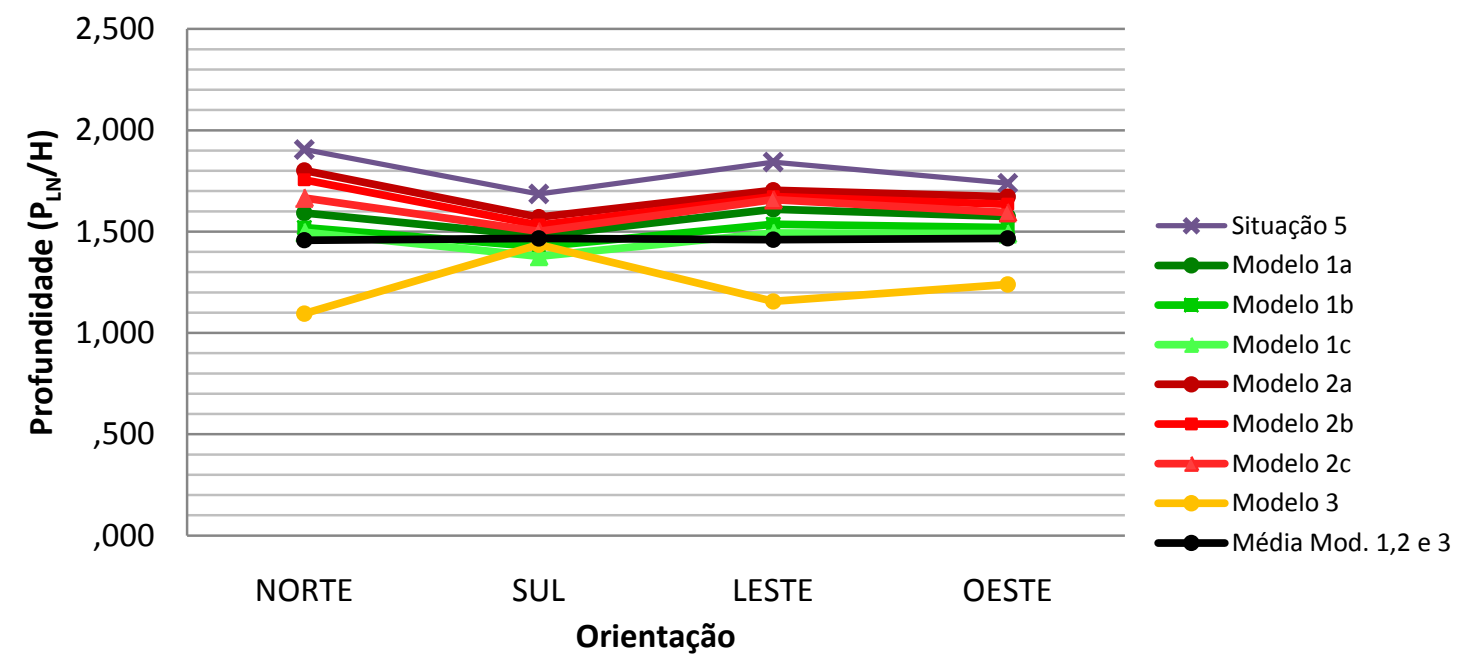

Figura 15 - Média por orientação da situação 5 e dos modelos 1, 2 e 3 


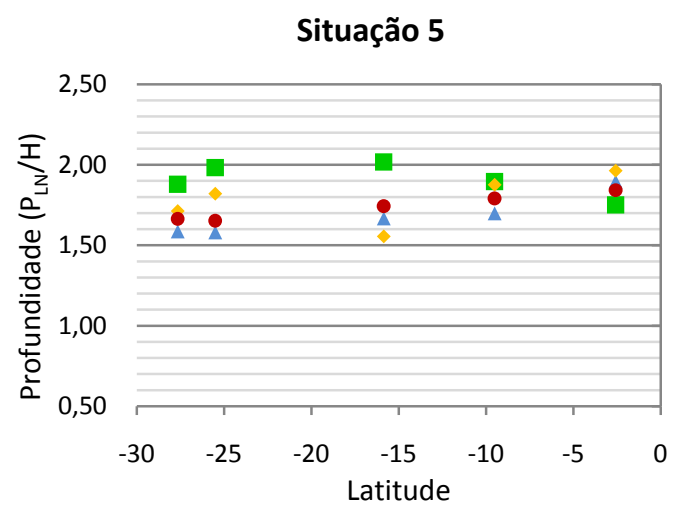

Figura 16 - Resultados da situação 5 para 5 latitudes

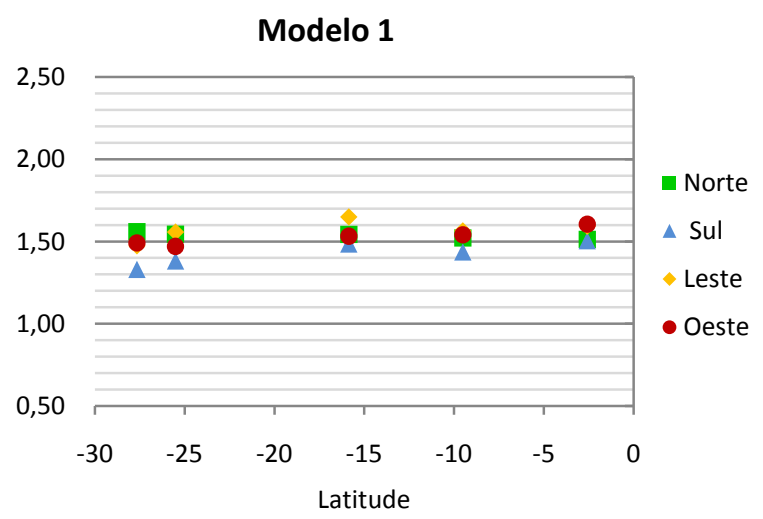

Figura 17 - Resultados do modelo 1

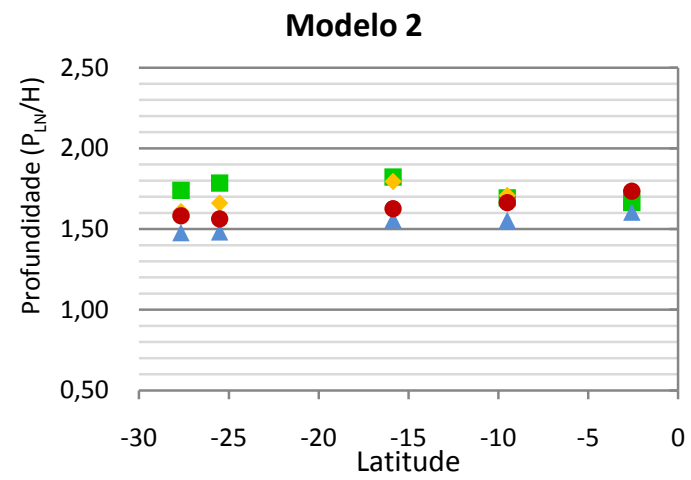

Figura 18 - Resultados do modelo 2

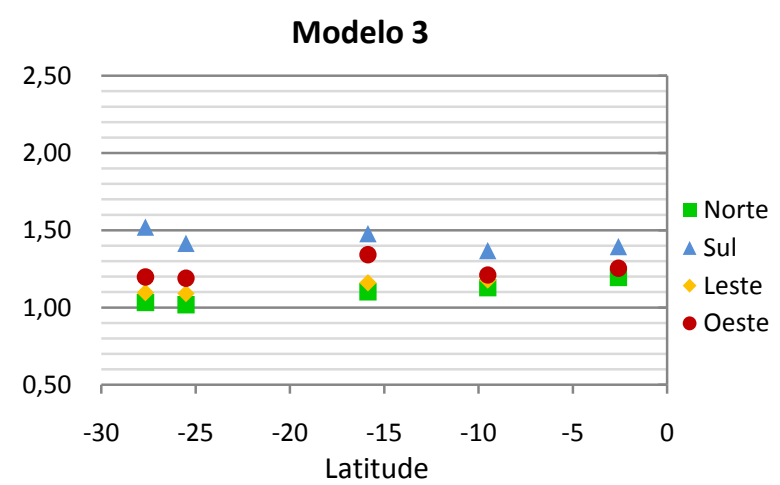

Figura 19 - Resultados do modelo 3 


\section{Verificação da aplicabilidade dos resultados (2 Etapa)}

O valor encontrado indica que ambientes com proteção solar (do tipo beiral ou marquises, proteções verticais, ou varandas com até $1,50 \mathrm{~m}$ ) devem ter a profundidade máxima de 2,11 vezes a altura da janela para garantir 60 lux em $70 \%$ do ambiente em $70 \%$ das horas do ano que possuem luz natural. Para verificar a aplicabilidade desse valor, este foi testado em uma amostra de 20 ambientes reais, 3 de edificações localizadas em Florianópolis e 17 em Brasília.

Destaca-se que, para a verificação da aplicabilidade do valor do limite da profundidade do ambiente em relação à altura da verga da janela, os ambientes selecionados possuem proteção solar nas aberturas de diferentes padrões (horizontal, vertical e mista) e tamanhos, e não é conhecida a refletância das proteções. O processo de verificação da aplicabilidade do valor da profundidade-limite do ambiente em relação à altura da janela foi realizado conforme o exemplo da Figura 20.

Ao verificar a relação da profundidade dos 20 ambientes selecionados com a altura de sua respectiva janela, verificou-se que apenas $45 \%$ deles atenderam ao limite da profundidade. Essa porcentagem foi considerada pequena para o total da amostra, sendo, portanto, pouco aplicável à realidade das edificações residenciais.

O uso de proteção solar reduz a iluminação natural nos ambientes internos, trazendo, no entanto, outros benefícios, como a redução do ofuscamento e da carga térmica excessiva. Visto que a intenção é incentivar o uso de elementos de proteção solar em fachadas, sugere-se reduzir a autonomia espacial da luz natural, de $70 \%$ da área do ambiente para $50 \%$, possibilitando o aumento da profundidade-limite dos ambientes com proteção solar. Isso permite aos ambientes que possuam elementos de proteção solar uma exigência menor com relação à luz natural, compensada pelo melhor controle da insolação, com consequências positivas no ambiente. $\mathrm{O}$ valor dessa redução foi, no momento, aleatório, necessitando ainda de aprofundamentos, que serão feitos em pesquisas posteriores. No entanto, a nova proposta de versão regionalizada do $\mathrm{LEED}^{3}$ indica que a exigência de luz natural nos espaços poderá ser reduzida para $50 \%$, sendo, portanto, coincidente com essa redução. Dessa forma, ambientes com proteção solar devem garantir 60 lux em 50\% do ambiente durante $70 \%$ das horas do ano em que possuem luz natural (horário variado de acordo com a latitude). Com essa correção, o valor do limite da profundidade do ambiente passou para 2,95 vezes a altura da janela.

Assim, verificou-se a aplicabilidade do valor de 2,95 vezes a altura da janela nos 20 ambientes selecionados. O resultado indicou que $80 \%$ dos ambientes atenderam ao limite da profundidade de 2,95 vezes a altura da janela, porcentagem considerada satisfatória, permitindo a aplicação em casos reais.

A Tabela 8 apresenta os resultados dos ambientes utilizados para verificação da aplicabilidade dos resultados, com informações sobre o ambiente e a conferência do atendimento dos valores-limite da profundidade de 2,11 e de 2,95 vezes a altura da janela.

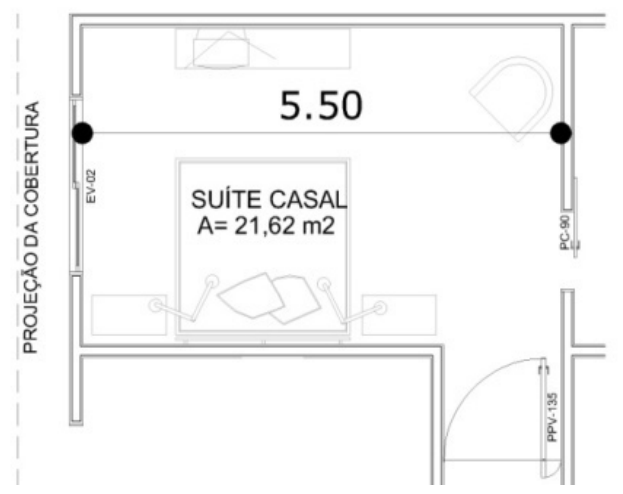

\author{
Localização: Brasília \\ Profundidade: 5,50 m \\ Dimensões da abertura: 2,00x2,60 m \\ Altura da porta: 2,60 m \\ Aplicação do valor de 2,11: \\ $\mathrm{P} \leq 2,11 \times \mathrm{H}$ janela \\ $5,5 \mathrm{~m} \leq 5,48 \mathrm{~m}$-> Não Atendeu \\ Aplicação do valor de 2,95: \\ $\mathrm{P} \leq 2,95 \times \mathrm{H}$ janela \\ $5,5 \mathrm{~m} \leq 7,67 \mathrm{~m}->$ Atendeu
}

\title{
Figura 20 - Exemplo do processo de verificação da aplicabilidade do valor da profundidade-limite do ambiente em relação à altura da janela
}

\footnotetext{
${ }^{3}$ Comitê LEED_EB_OM 2009 - Qualidade Ambiental Interna (IAQ) - Reunião Regionalização LEED - crédito adaptado “Iluminação Natural e Vistas", Green Building Council Brasil.
}

54 Albuquerque, M. S. C.; Amorim, C. N. D. 
Tabela 8 - Resumo da verificação da aplicabilidade dos resultados para ambientes com proteção solar

\begin{tabular}{c|l|l|c|c|l|l}
\hline $\mathbf{N}^{\mathbf{0}}$ & Cidade & Ambiente & $\begin{array}{c}\text { Profundidade } \\
\text { ambiente }\end{array}$ & $\begin{array}{c}\text { Altura } \\
\text { janela }\end{array}$ & $\begin{array}{c}\text { P } \leq \mathbf{2 , 1 1} \text { x H } \\
\text { janela }\end{array}$ & $\begin{array}{c}\text { P } \mathbf{2 , 9 5} \text { x H } \\
\text { janela }\end{array}$ \\
\hline $\mathbf{1}$ & Florianópolis & Sala & 7,35 & 2,10 & Não atendeu & Não Atendeu \\
$\mathbf{2}$ & Florianópolis & Sala & 5,00 & 2,70 & Atendeu & Atendeu \\
$\mathbf{3}$ & Brasília & Cozinha & 10,48 & 2,30 & Não Atendeu & Não Atendeu \\
$\mathbf{4}$ & Brasília & Quarto & 4,47 & 2,30 & Não Atendeu & Atendeu \\
$\mathbf{5}$ & Brasília & Quarto & 4,00 & 2,46 & Atendeu & Atendeu \\
$\mathbf{6}$ & Brasília & Quarto & 3,54 & 2,46 & Atendeu & Atendeu \\
$\mathbf{7}$ & Brasília & Quarto & 4,56 & 2,46 & Atendeu & Atendeu \\
$\mathbf{8}$ & Brasília & Sala & 8,90 & 2,30 & Atendeu & Atendeu \\
$\mathbf{9}$ & Brasília & Quarto & 5,75 & 2,60 & Não Atendeu & Atendeu \\
$\mathbf{1 0}$ & Brasília & Sala & 6,50 & 2,60 & Não Atendeu & Não Atendeu \\
$\mathbf{1 1}$ & Brasília & Cozinha & 5,57 & 2,60 & Não Atendeu & Não Atendeu \\
$\mathbf{1 2}$ & Brasília & Quarto & 4,00 & 2,60 & Atendeu & Atendeu \\
$\mathbf{1 3}$ & Brasília & Quarto & 5,50 & 2,60 & Não Atendeu & Atendeu \\
$\mathbf{1 4}$ & Brasília & Escritório & 3,55 & 2,60 & Atendeu & Atendeu \\
$\mathbf{1 5}$ & Brasília & Quarto & 3,24 & 2,20 & Atendeu & Atendeu \\
$\mathbf{1 6}$ & Brasília & Quarto & 4,23 & 2,20 & Atendeu & Atendeu \\
$\mathbf{1 7}$ & Brasília & Sala & 4,46 & 2,20 & Não Atendeu & Atendeu \\
$\mathbf{1 8}$ & Brasília & Sala & 9,58 & 2,20 & Não Atendeu & Não Atendeu \\
$\mathbf{1 9}$ & Brasília & Sala & 6,08 & 2,20 & Não Atendeu & Não Atendeu \\
$\mathbf{2 0}$ & Brasília & Quarto & 4,50 & 2,30 & Não Atendeu & Atendeu \\
\hline
\end{tabular}

\section{Conclusões}

Diversos aspectos são consequências do uso da luz natural em edificações residenciais, entre os quais a maior qualidade ambiental, a saúde dos ocupantes e a possibilidade de economia energética. No entanto, para o uso correto da iluminação natural é fundamental o desenvolvimento de indicações que orientem e facilitem o processo de projeto, com relação às variáveis arquitetônicas da edificação.

Neste trabalho, foram desenvolvidos quatro modelos e realizadas 336 simulações computacionais de medidas dinâmicas, verificando a influência de algumas variáveis arquitetônicas, especificamente a profundidade do ambiente e das proteções solares no comportamento da luz natural em ambientes residenciais no contexto territorial brasileiro.

Como resultado, obteve-se que ambientes residenciais sem elementos de proteção solar nas aberturas e com características consideradas padrão - abertura em torno de 1/6 da área de piso, alta refletância do teto (80\%), paredes com refletância média (60\%) e piso de baixa refletância (30\%) - que possuem uma profundidade limite de 2,57 vezes a altura da janela podem garantir uma iluminância de 60 lux em aproximadamente 70\% do ambiente em $70 \%$ das horas com luz natural, considerando o horário de ocupação em que há luz natural disponível, de acordo com o contexto territorial brasileiro. Esse valor da profundidade- limite em relação à altura da janela para ambientes sem proteção solar foi inserido no RTQ-R no item de Bonificações em Iluminação Natural (BRASIL, 2010b, p. 105). Cabe ressaltar que essa indicação aplica-se a ambientes com proporções similares ao ambiente simulado com área de abertura correspondente a 1/6 da área de piso. Para outros casos, a alternativa da simulação computacional aparece como solução para uma análise mais específica.

No caso de ambientes com proteção solar, para garantir 60 lux em $50 \%$ da área do ambiente em $70 \%$ das horas com luz natural, a profundidadelimite deve ser no máximo 2,95 vezes a altura da janela. A redução da exigência para 50\% do ambiente, apesar de coincidir com a nova indicação de regionalização do LEED, foi considerada preliminar para efeito do RTQ-R, por não terem sido testados de forma abrangente outros tipos de proteção solar existentes. Nesse caso, portanto, essa condição foi adotada no RTQ$\mathrm{R}$ apenas para estabelecer o critério a ser atendido pelo método de simulação exposto no Regulamento.

Pretende-se dar continuidade ao presente trabalho, aperfeiçoando outras indicações projetuais para a obtenção de boa iluminação natural em ambientes internos, para atender mais adequadamente às especificidades relacionadas às variáveis arquitetônicas, como geometria do ambiente (largura e pé-direito), forma das aberturas (dimensão e posição), característica dos vidros das 
aberturas, refletância das superfícies, outras tipologias de proteção solar, entre outros. Dessa maneira será possível a criação de outras regras aplicáveis a um maior número de tipologias, contribuindo para as boas práticas no projeto com luz natural e colaborando também com a eficiência energética em edificações.

\section{Referências}

ALUCCI, M. P. Manual Para Dimensionamento de Aberturas e Otimização da Iluminação Natural na Arquitetura. São Paulo: Fauusp, 2007. v. 1.

AMORIM, C. N. D. Diagrama Morfológico Parte I: instrumento de análise de projeto ambiental com uso de luz natural. Paranoá Cadernos de Arquitetura e Urbanismo, Brasília, DF, n. 3, P. 57-76, 2007.

\section{ASSOCIAÇÃO BRASILEIRA DE NORMAS} TÉCNICAS. NBR 5413: iluminância de interiores. Rio de Janeiro, 1992.

\section{ASSOCIAÇÃO BRASILEIRA DE NORMAS} TÉCNICAS. NBR 15215-1: iluminação natural: parte 1: conceitos básicos e definições. Rio de Janeiro, 2005a.

ASSOCIAÇÃO BRASILEIRA DE NORMAS TÉCNICAS. NBR 15215-2: iluminação natural: parte 2: procedimentos de cálculo para a estimativa da disponibilidade de luz natural. Rio de Janeiro, 2005b.

\section{ASSOCIAÇÃO BRASILEIRA DE NORMAS} TÉCNICAS. NBR 15215-3: iluminação natural: parte 3: procedimento de cálculo para a determinação da iluminação natural em ambientes internos. Rio de Janeiro, 2005c.

ASSOCIAÇÃO BRASILEIRA DE NORMAS TÉCNICAS. NBR 15215-4: iluminação natural: parte 4: verificação experimental das condições de iluminação interna de edificações: método de medição. Rio de Janeiro, 2005d.

\section{ASSOCIAÇÃO BRASILEIRA DE NORMAS TÉCNICAS. NBR 15575-1: edifícios} habitacionais até 5 pavimentos: desempenho: parte 1: requisitos gerais. Rio de Janeiro, 2008.

BRASIL. Instituto Nacional de Metrologia, Normalização e Qualidade Industrial. Portaria ${ }^{\circ}$ 449, de 25 de novembro de 2010. Regulamento Técnico da Qualidade - RTQ para o Nível de Eficiência Energética de Edificações Residenciais (RTQ-R). Rio de Janeiro, 2010b.
COFAIGH, E. O.; FITZGERALD E.; ALCOCK

R., LEWIS J. O.; PELTONEM V. and

MARUCCO A. A Green Vitruvius: principles and practice of sustainable architectural design. London: James \& James, 1999.

DIDONÉ, E. L. A Influência da Luz Natural na Avaliação da Eficiência Energética de Edifícios Contemporâneos de Escritórios em Florianópolis. 174 f. Florianópolis, 2009. Dissertação (Mestrado em Arquitetura e Urbanismo) - Universidade Federal de Santa Catarina, Florianópolis, 2009.

DEUTSCHES INSTITUT FÜR NORMUNG. DIN 5034: Tageslicht in Innenräumen. Berlin, 1997.

DEUTSCHES INSTITUT FÜR NORMUNG. DIN V 18599-4: energy performance of buildings: part 4: lighting. Berlin, 2005.

ENERMODAL ENGINEERING. Public Works \& Government Services. Daylighting Guide for Canadian Commercial Buildings. Canada, 2002.

FERNANDES, J. T. Código de Obras e Edificações do DF: inserção de conceitos bioclimáticos, conforto térmico e eficiência energética. 249 f. Brasília, DF, 2009. Dissertação (Mestrado em Arquitetura e Urbanismo) Universidade de Brasília, Brasília, 2009.

FIGUEIRÓ, M. A Luz e a Sua Relação Com a Saúde. Lume, São Paulo, v. 8, n. 44, jun. 2010.

ILLUMINATING ENGINEERING SOCIETY OF NORTH AMERICA. The Lighting Handbook. $9^{\mathrm{TH}}$ ed. New York: IESNA, 2000.

MARDALJEVIC, J. Simulation of Annual Daylighting Profiles for Internal Illuminance.

Lighting Research \& Technology, v. 32, n. 2, p. 111-118, 2000.

MARTAU, B. T. A Luz Além da Visão. Lume, v. 7, n. 38, jun. 2009.

MINISTÉRIO DE MINAS E ENERGIA. Balanço Energético Nacional 2009: ano-base 2008. Brasília: MME, 2009.

O'CONNOR, J. et al. Tips for Daylighting with Windows. Lawrence Berkeley National Laboratory, 1997. LBNL report 39945.

REINHART, C. F. A Simulation-Based Review of the Ubiquitous Window-Head-Height to Daylit Zone Depth Rule-of-Thumb. In: INTERNACIONAL BUILDING SIMULATIONS CONFERENCE, 9., Montreal, 2005.

Proceedings... Montreal: IBPSA, 2005. 
REINHART, C. F. Tutorial on the Use of Daysim simulations For sustainable Design. Cambridge: Harvard University Graduate School of Design, 2010.

REINHART, C. F.; MARDALJEVIC, J.;

ROGERS, Z. Dynamic Daylight Performance Metrics For Sustainable Building Design. Leukos, v. 3, n. 1, 2006.
REINHART, C. F., WALKENHORST, O.

Dynamic RADIANCE-Based Daylight

Simulations For a Full-Scale Test Office With Outer Venetian Blinds. Energy \& Buildings, v. 33, n. 7, p. 683-697, 2001.

ROBERTSON K. Daylighting Guide for Buildings, Distributed Through the Canadian Mortgage \& Housing Corporation. Canada, 2005.

VIANNA, N.; GONÇALVES, J. C. Iluminação e Arquitetura. São Paulo: UniABC Virtus, 2007.

Revista Ambiente Construído

Associação Nacional de Tecnologia do Ambiente Construído

Av. Osvaldo Aranha, 99 - 3o andar, Centro Porto Alegre - RS - Brasil

CEP 90035-190

Telefone: +55 (51) 3308-4084

Fax: +55 (51) 3308-4054

www. seer. ufrgs. br/ ambienteconstruido

E-mail: ambienteconstruido@ufrgs.br

${ }^{4}$ O projeto QualiHIS, desenvolvido entre 2007 e 2009, foi financiado pelo programa Habitare, com recursos do CNPq e da Finep, com contrapartida da Caixa Econômica Federal e órgãos promotores de construção habitacional. 